mixture of 90 per cent of "paraffin spirit" and 10 per cent of bone oil with the addition of solid lithium. The hard residue was crushed, and was found to contain some transparent crystals which were identified as diamond. A combustion carried out on 14 mgm. gave $97 \cdot 85$ per cent of carbon.

In spite of the small number of successes, it is difficult to believe that Hannay was mistaken in his identification. As his solid residues contained nitrogen, he was inclined to believe that the diamonds owed their origin to the nitrogenous compounds used and not to the hydrocarbons, a point which would have an important bearing on the origin of the natural crystals. Although he announced his intention of making further experiments, no later paper on this subject appeared, although he published work on other subjects so late as 1894.

Moissan attempted to repeat Hannay's experiments, but could not succeed in welding the tubes. Parsons also tried the same materials and pressures, but without success, and the work might have boen forgotten but for the fortunate fact that twelve of the minute crystals obtained by Hannay in 1879-80 had been deposited in the mineral collection of the British Museum (Natural History). None of the crystals obtained by either Moissan or Parsons has been traced.

The whole subject has been transformed by recent work with X-rays. Mrs. K. Lonsdale and Mr. F. A. Bannister ${ }^{8}$ were able to examine by X-ray mothods the crystals preserved at South Kensington, and found some of them to be true diamonds. What, however, was still more remarkable was that they showed the characteristics of the rare (type II) diamond described by Sir Robert Robertson and his colleagues ${ }^{9}$, which differ profoundly in optical and electrical properties from the normal type I. One was definitely identified by its X-ray pattern as of type II, while the others showed the highly laminated condition which is associated with that type. Since type II only occurs in about one per cent of natural diamonds, the probability that Hannay's crystals were astually obtained artificially is greatly strengthened, and the accuracy of his statements vindicated. It is clear that the new observations re-opan the whole quastion, and that, in spite of the failure of Parsons and Duncan. to convince themselves that they had obtained true diamonds, and their consequent rejection of earlier work, it may prove that the methods of high pressure and high temperature common to the work of Hannay, Moissan and Parsons do actually succeed in converting a minute proportion of the carbon contained in the materials into diamond, although the factors determining such a transformation remain very obscure, while the fact has to be borne in mind that all diamonds, exposed to a sufficiently high temperature, are changed to graphite. A very old problem thus comes again into prominence, but with the advantage of experimental methods of rapid identification which were not available to the earlier workers.

1 Papers in C:R. Acad. Sci. from 1894 onwards. Summarized in "Le Four électrique": "Fnglish translation, "The Electric Furnace" Four électrique" ;
(Easton, Pa, 1920).

2 Le Chatelier, H., "Leçons sur le carbone" (Paris, 1926), p. 24.

3 Parsons, C. A., Proc. Roy. Soc., A, 79, 532 (1907); J. Inst. Metals, 20, 5 (1918); Phil. Trans., A, 220, 67 (1920).

4 Crookes, W., "Diamonds" (London, 1909).

5 NATURE, 121, 799 (1928).

Travers, M. W., Chem. and Ind., 17, 507 (1939).

7 Hannay, J. B., Proc. Roy. Soc., 30, 188, 450 (1880).

- Bannister, F. A., and Lonsdale, K., NAture, 151, 334 (1943).

- Robertson, R., Fox, J. J., and Martin, A. E., Phil. Trans., A, 232, $4{ }_{10}(1934)$.

\section{NATURE AND USES OF SEAWEEDS*}

\author{
BY R. E. MARION DELF \\ Westfield College, University of London
}

T $\mathrm{N}$ the last fifty years or so there has been much 1 progress in our knowledge of seaweeds, but until comparatively recently, mainly from the botanical point of view. Until this century, botanists had been chiefly concerned with nomenclature and with the major fasts of structure and reproduction of a few commoner typas. But early in this century, newer lines of investigation were being developed, involving the systematic analysis of veg otational units and the study of the complex relations between the plant and its environment. Mr. A. D. Cotton has made an ecological survey of the marine algæ of Clare Island, off the coast of Ireland. This study, the first of its kind by a British author relating to the algæ, becams and has remained a classic for other workers in this field.

Another and rather different line of advance during the last thirty to forty years has been in the study of the life-histories of the marine alga, stimulated in Great Britain by the work of Lloyd Williams (1906) and in France by that of Sauvag zau (1915). Lloyd Williams found that in the brown alga Dictyota dichotoma, Lamour, two generations, externally similar, followed one another, each divoted to a different kind of reproduction, one with sexual, the other with asexual reproduction. He also found a definite rhythm of reproduction, closely related to tidal phenomena. Sauvageau made the even more striking discovery that the innum rable swimming spores produced by the different species of Laminaria (reckoned by Yendo as about 84,000 per square millimetre) could be made to gorminate, whon they developed into minute branched threads requiring high magaification for observation. 'These ultimately gave rise to gametes, which after fertilization reproduced the early stages of the original typ 3 of plant.

The effect of this discovery on the botanical world was far-raashing. It has been found that this type of alternation is characteristic of the whole family of Laminarias, though by no means limited to it. In miny apparently annual typэs, like the familiar 'sэa bootlasэs' (Chorda filum, Lamour), although the visible thallus or 'bootlase' dies down at the end of the summor, a microscopic sexual generation is pro. duced and carries on the cycle unseen beneath the watərs during the winter months.

In respect of the red alg e, Yamanouchi followed the still more complicated life-history of Polysiphonia violacea, Harv. (1906), and this became the forerunner of many similar investigations, notably those of Svedelius (of Copənhægən) and of Kylin (of Bergen). Although most red alge have alternation between two similar plants, it is beginning to be realized that others have great difference in form between their alternate generations, even when both are equally visible to the naked eye. To establish their identity is then no easy matter, for most marine algæ are dificult to cultivate under artificial conditions. It is not surprising that nomenclature of the marine algæ is in a backward state, since in the past it has been founded largely on the observation of material (often dried) apart from a knowledge of life-cycles,

* Substance of a paper read before the Royal Society of Arts on May 12 . 
or of other differences in form brought about by the influence of a particular environment. There is, as yet, no systematic record of the algal vegetation of our coasts. Such accounts as are available relate to particular localities, usually to summer resorts where rocks are relatively accessible, or to regions within the sphere of influence of marine biological stations, like that at Plymouth or at Port Erin, in the Isle of Man. Little is known of the interaction between the animal and plant population of the shore.

Whereas some seaweeds are permanently submerged in pools or in deep water, the majority are amphibious, in that they spend part of their lives under water, part exposed to the air, owing to the receding of the tide. Unlike some amphibious animals, they are fixed to some substrate, so that they must endure, at least temporarily, all atmospheric vicissitudes. They may be heated by the sun, cooled by wind or frost and dried by the action of wind and sun together. The sea-water adhering to them may be diluted by rain or concentrated to brine by evaporation. The time of exposure varies with the height of the tide and the position on the shore. Those near the upper limits have longer exposure, and unless they are to be found in fairly deep pools, only species which are resistant to desiccation can survive in this region. For the same reason, in hot climates, intertidal vegetation is much more sparse than on temperate shores. The middle regions of the shore are the most densely populated by both animals and plants, and here competition for space and light is the keenest; while at the lower limits, the depth of water is such that there is too little light for any but shade plants (mostly red algæ) or brown ones like the Laminarias with long stipes which bring the flat fronds up towards the surface.

On the whole, in temperate climates there is a marked tendency towards zonation-at low water, the higher and middle regions of rock or shore being predominantly brown, from the more numerous of brown algæ, the lower regions red or brownish-red. The underlying causes of this zonal distribution has of recent years been the subject of much discussion.

All this is not merely of general or academic interest. If, as seems not unlikely, seaweeds may become an asset of some commercial importance, conditions of their growth, regeneration and harvesting must be more fully explored. In suitable localities and on suitable shores it may then be worth while to cultivate the more profitable kinds. Something of the kind is, indeed, already being attempted on a small scale in the so-called Fucus farms of Northern Ireland, where the harvest is utilized locally for manuring the fields. These farms are located in somewhat sheltered bays where, at low water, there is a flat stretch of sand strewn with large stones, boulders or rocks. The kind of alga which develops depends partly on the nature of the anchorage, partly on the position with respect to tidal range. Thus the boulders and larger stones of the upper middle tidal zone become covered with Ascophyllum; the smaller stones wedged between bear Fucus vesiculosus L., the common bladder wrack; while at lower levels both stones and rocks bear ${ }^{\prime}$. serratus L.

These three species form the bulk of the harvest, and when cut are regenerated from sporelings; but apparently two or three years must elapse between successive harvests from the same area, and no attempts have been made, so far as I know, to improve the yield or to shorten the period of regeneration and maturation; more stones are sometimes added, however, and this demands a certain amount of judgment as to size and suitability. At the present time, a number of research workers at Port Erin are engaged in studying the growth-rate and reproduction of certain seaweeds of possible future importance with a view to their more rational harvesting, and it is to be hoped that these and other investigations will be continued and expanded in post-war years.

Seaweeds have been used extensively in the East for many years ; in Japan especially for food, manure and glue. Early in this century, when commercial developments were visualized, a definite cultivation was inaugurated there. For this purpose, suitable rock-surfaces were cleared of weed during the period of reproduction. After a time, the water being full of their spores, a new crop appeared, which successfully established itself in spite of competition with other kinds which usually arrived first.

The Japanese botanist Yendo was instructed to study and report on the conditions for success and also on the causes of failure in certain areas. With the help of this report and the practical experience of fishermen who were employed in the cultivation, instructions were drawn up and circulated as to planting and harvesting the appropriate seaweeds. On certain reefs, constantly removing crops of Laminaria favoured the spread of a useless plant, Phyllospadix (one of the few submarine flowering plants), which covered the surface with its undergrowth and smothered the young plants of Laminaria. The removal of the Phyllospadix was therefore made compulsory, a special tool being designed to facilitate the periodic weeding.

Yendo pointed out that seaweeds, like other plants, had their peculiarities which must be considered: for example, Gloiopeltis, from which much glue is made, flourishes best on smooth, hard surfaces, in positions where there is spray or foam ; on the other hand, rough surfaces suit mcst seaweeds, Laminarias requiring a hard rock, like quartzite, pitted with numerous depressions. Porphyra is grown by planting small twigs obliquely in crevices in areas where the salinity is high. This gives the greatest number of sporelings : the twigs are then transplanted to places where the salinity is lower, in order that the finest fronds should develop from the sporelings.

Not all marine plants are seaweeds in the stricter sense of the word. Zostera, the eel-grass, for example, which occurs in relatively quiet waters, is a flowering plant, producing flowers and fruits beneath the waves. The true seaweeds, on the other hand, are plants of a much lower order in the evolutionary scale of plant life, as will have been realized in connexion with the life-cycles to which reference has already been made.

The great differences between the marine algæ and the flowering plants are seen, however, in many other features-for example, in their general organization, the plant having no root system, no buds or flowers, and, of course, no seed production. It is also seen in their construction, which has little in common with that of flowering plants even when these, like Zostera, have the same habitat.

The building of a structure may be said to depend on three things-on materials, the building unit and on design. The building materials of the seaweeds are various mucilaginous and gelifying substances, cellulose playing little or no part in the composition of their walls. The unit of construction is the branched thread or filament, that is, a chain of cells rather than single cells aggregated into tissues. The whole 
structure is fabricated of variously interwoven threads, some of which may have walls of considerable thickness. Some of the threads send out lateral branches, the tips of which become compacted together, giving a firm exterior to the plant. In many surf plants, the threads become intricately intertwined, as the thallus is tossed about by wave action. Mucilaginous substances, believed to be derived from the cell walls, cement the whole together. The architecture of most seaweeds is such as to give flexibility with either elasticity and extensibility as in Ascophyllum and Himanthalia, or with a certain tensile resistance \&s in Fucus. The peculiar wall material also serves another purpose, readily absorbing water and retaining it with tenacity when exposed to drying. It is these wall substances which promise to become of great commercial importance.

The biochemical features of algal products have been explored from several angles-their pigmentation, their metabolic products and their wall substances differing considerably in the three great groups. Most of this lies beyond the scope of the present paper; but I should like to note in passing the success of a plant biochemist. Dr. Paul Haas (1931), in capturing and identifying the source of the characteristic smell of one of the common red seaweeds, Polysiphonia lanosa, parasitic on the brown alga Ascophyllum nodosum. The fresh alga was placed in a flask, kept at $30^{\circ} \mathrm{C}$. by means of a water bath. Air was drawn through and carried over a volatile substance, which dissolved in water, alcohol or acetone. Afterwards this was found to be identical with methyl sulphide.

\section{Utilization of Seaweeds}

Generally speaking, seaweeds are utilized in three principal ways : in connexion with agriculture, as food or medicine, and for industrial purposes.

1. Seaweeds in agriculture. In agriculture, seaweeds are used as fodder or as manure. The seaweed may be fed fresh (sheep, for example, are allowed to graze on the rocks at low water in the Orkneys). In the north of Scotland, Pelvetia is brought to the boil and after addition of oatmeal is used to feed calves. Dried seaweed, ground to a meal, is used in some districts or, alternatively, the fresh seaweed. is stored in layers with hay between, forming a kind of silage as winter feed. Laminaria saccharina was fed to horses with varying success in France during the War of 1914-1918. Reports of the results are not always in accord, perhaps because of seasonal variations in the food value of the alga, since the sugar content is at a maximum in the autumn and it seems that the sugar (stored as laminarin) is probably the most easily digested of the constituents. In New Zealand, seaweed (Macrocystis, Hormosira) is found. to benefit cattle grazing on poor pasture land. In America, seaweed meal has improved health and fertility in cattle and in chickens, when fed as a small proportion of the daily diet.

The use of algæ as manure in maritime situations is widely practised. It is well known on coasts of Brittany, on various coasts of Ireland, in the north and west of Scotland and on coasts of northern Europe. Naturally, driftweed is largely collected for the purpose, but harvesting the cut seaweed is also practised where the coast is suitable. In north-west France the collection of algæ has been regulated by statute for some hundreds of years. The manurial value is probably due to the organic constituents, which provide bulk for the soil, as well as for the mineral salts. There is little nitrogenous value in most seaweeds, but the different kinds of laver (Ulva and Porphyra) are said to be exceptional in this respect.

2. Seaweeds as food or medicine. The use of seaweeds for food has been known from very early times. They are greatly valued in the East-in Japan, coasts of China and Malay; but they are also used on the north and north-west coasts of Europe.

Laver (Ulva latissima and Porphyra laciniata), dulse (Rhodymenia palmata) and murlins (Alaria esculenta) are eaten as vegetable on the coasts of Ireland and Scotland and no doubt elsewhere, and may be familiar in this capacity to a number of people. The name of sea lettuce for Ulva latissima is suggestive.

Pink laver is produced commercially in Japan, and the washed, pressed fronds are regarded as a delicacy. It is used under the name of akusanori for soups, as a vegetable, or may even be eaten raw. The sample I happen to possess claims to be especially finebut it seems rather tasteless to the Western palate. In Great Britain, probably carrageen moss (Chondrus crispus and Gigartina spp.) is the most widely utilized of seaweed products, valued for the jelly-like nature of its hot-water extract. In the War of 1914-18, carrageen was in demand to replace gelatin, which was in short supply.

Little seems to be known with any certainty as to the food value of even the most edible weeds. It is usually considered that their mineral content is of value, especially the iodides, which are characteristic of many brown and some red kinds; their gelatinous substances are probably not digested by man, but may be useful in providing bulk without irritation. There are algæ like Laminaria saccharina and Alaria esculenta, which seasonally store sugars, but it seems doubtful whether these particular sugars can be digested, at least by human beings. It is on record, however, that the digestive juices of snails and limpets are very efficient in this respect.

Seaweeds as food have never been very popular in England, but several preparations are marketed at the present time and sold as "seaweed salt". This is recommended as giving a daily quota of iodine in natural form, to maintain health or to correct deficiency in those with a tendency to goitre. Some of these preparations claim to be the dried and finely powdered weed. In conformity with this claim, the powders, on moistening, swell to a gelatinous mass which has a taste decidedly suggestive of seaweed. The iodine content of certain seaweeds is remarkable in that it has to be derived from the sea water, in which only traces occur. The algæ are believed to absorb water over their whole surface; they must have the power not only to absorb the traces present, but also to accumulate them within. The physiological mechanism of this accumulation is little understood.

Among the brown algæ, the Laminariaceæ are relatively rich in iodine, but the Fucacere are also used as sources of iodine in some localities. A number of red algæ also store iodine (for example, species of Iridea and Asparagopsis), while a few have special enlarged superficial cells rich in iodides : these red algæ, however, do not occur in sufficient abundance, at least in Europe, to serve as a source of iodine on any commercial scale. 
3. Commercial products. The manufacture of potash and other substances from kelp* (derived from the larger brown algæ) fell into disuse in the latter part of the nineteenth century, when cheaper sources were discovered from mineral deposits. In the present century, interest has grown in the algæ as a source of mucilaginous substances utilized in many ways, especially in Japan, Great Britain and the United States. These mucilaginous substances can be divided roughly into two classes with differing chemical and physical properties: those from the brown and from the red alga respectively.

The mucilaginous products of the higher brown algæ can be extracted by boiling the fresh material with a dilute solution of sodium carbonate. After a time, the tissues swell and lose their shape; the mass is then filtered through cloth, and on acidifying there forms a thick, slimy substance recognized by Stanford in 1862 as of definite chemical composition and named by him first algin, later alginic acid, since it formed a series of metallic salts, like a true acid.

In recent years, algin and its derivatives have been utilized for many commercial purposes. A study of the many patents granted in this period reveals something of the progress which has been made both on the technical side and in the chemical knowledge on which that progress must be based. It has been found, for example, that when treated with vulcarnizing agents, such as carbon disulphide or carbon tetrachloride, algin becomes a rubbery mass, which has been used to make rollers for typewriters, among other things.

By violently agitating an alkaline solution of algin with which a small proportion of tannic acid has been mixed, the whole emulsifies and may be poured upon a glass or polished surface, giving a transparent film resembling 'Cellophane'. It is claimed that this film is cheap, almost non-inflammable and less influenced by light than true 'Cellophane', which is apt to become very brittle. It has already been widely used as an inexpensive transparent wrapping for various classes of goods, or, at least, it was so used before restrictions on wrappings were in force.

The purified alkaline extract of the fresh seaweed may, alternatively, be forced through a fine aperture, forming a viscous thread which is then spun into a bath containing a mixture of furfurol, caustic soda, formalin and other substances. By this means a kind of 'artificial silk' is produced, which after further treatment is washed and finally sized with an ammoniacal solution of algin under pressure.

This thread, however, as first produced, was not strong enough for weaving, and moreover was not sufficiently resistant to soaps containing a proportion of alkali. Further processes involving treatment of the thread with salts of chromium or beryllium are alleged to have overcome these difficulties. The chromium salts, being coloured, were not so suitable for subsequent dyeing, but the beryllium salts appear to be free from this objection. The strengthened thread so obtained will, no doubt, be tested in due course for weaving.

The Japanese claim to have produced an artificial wool from gulfweed (Sargassum spp.) by spinning the viscous thread into a bath, which had a crimping effect.

In recent years, salts of alginic acid have been obtained from species of Laminaria collected on the Atlantic coasts of Scotland. From this source,

* 'Kelp' was the name originally used for the ash of the larger brown seaweeds after burning. In America it has also been applied to the various brown algæ used for this purpose. the firm of Albright \& Wilson have been able to market a purified form of sodium alginate which has been given the trade name of 'Manucol'. The white powder dissolves in water to form extremely viscous solutions which are tasteless, odourless and almost colourless. It is claimed that these powders or their derived products have been utilized in connexion with a variety of industries, including production of food and medicines, and the manufacture of cosmetics, textiles, transparencies and plastics.

Alginates may be added to milk previous to the manufacture of milk powders ; in this way, the milk can be reconstituted by the addition of water, without causing sedimentation. Cocoa may be rendered more. 'soluble' by a similar addition.

The colloidal properties of alginates render them especially suitable as a base for creaming agents, for car polish and even for boiler feeds to prevent the deposition of 'fur'. In these and a number of other commercial products, alginates behave as 'protective' colloids, helping to keep in suspension or emulsion particles which would otherwise tend to settle as a sediment.

Although so many uses have been found for the salts of alginic acid, the chemical composition of the acid itself has been a subject of controversy. Stanford concluded that the molecule was a large one, including nitrogen $\left(\mathrm{C}_{76} \mathrm{H}_{80} \mathrm{~N}_{2} \mathrm{O}_{22}\right)$, but later work with purified materials has established that it is a polymer of $d$-mannuronic acid. Experiments of Bonniken appear to indicate that treating the alkaline salts with astringent agents causes a progressive polymerization of the original algin molecule, giving longer and more complex chain structure. It is these long-chain molecules which are important for the production of textile threads and are susceptible to contraction, giving the possibility of a crimping effect.

Two classes of colloidal substances can readily be extracted from red algæ, namely, mucilages and gels. The former may be dissolved out with cold or tepid water, the latter by boiling for a short time.

In Japan, at Osaki, a kind of seaweed glue called 'funori' is made from species of Gloiopeltis (chiefly $G$. coliformis and $G$. intricata). It is used for adhesives and for sizing paper, fibre or cloth. A more valuable product is agar-agar, the commercial name given to the gelatinous substance extracted by boiling water. During the last two decades, agar has been widely used in connexion with foods and medicines. As a laxative, it absorbs and retains water, besides acting as a lubricant. It is almost universally used as a basis for bacterial and fungal cultures, resisting liquefaction. Recently, however, a strain of bacteria, Vibrio agarlyticus, has been isolated which liquifies agar but not cellulose.

By far the greater part of the world's supply of agar came from Japan, but a considerable quantity has also been manufactured in California, though much is not sufficiently pure for bacteriological purposes. At the present time, investigations are being carried out in the United States and other countries, with the view of developing local supplies. The rich algal flora of the coasts of South Africa and New Zealand and of the west coasts of North America and Canada offer many possibilities, but even in the U.S.S.R. during the last ten years, an agar-producing industry has apparently been developed, utilizing algæ which occur on their maritime coasts and on the shores of the Black Sea. It has recently been announced that agar suitable for bacteriological purposes has been 
obtained from certain seaweeds in South Africa, New Zealand and in Britain. This is being further explored.

To obtain a pure agar, the freshly collected algæ are bleached in the sun for some days, the process being hastened by sprinkling at intervals with fresh water. The bleached algæe are then boiled with water (Japan) or treated with steam (United States) and the resulting mass strained through cloth. The clear liquid is poured into shallow troughs to set, and the jelly cut into narrow strips. In Japan, the process is carried out in cold weather, so that the strips contract, expelling water ; in the United States the same result is obtained by artificial refrigeration. In either case, the expelled water is drained off, and the remaining jelly dried and shredded for packing.

Agar prepared in this manner has been analysed and is described as "a galactan with sugar units of unusual structure". Carrageen mucilage from Chrondrus crispus is a "polysaccharide ester of sulphuric acild by the acetolysis of which two galactans were isolated". Both these products are water soluble. According to Tschudy and Sargent, the two American species of Gigartina require a preliminary soaking and subsequent boiling in lime water or 2 per cent calcium chloride in order to extract a substance giving a firm jelly. Subsequent treatment (straining, cooling and drying) appears to be the same as for the water-soluble derivatives of other types. It appears, therefore, that a number of different but probably closely related substances with similar physical characteristics are included under the general term agar. The amount which can be extracted appears to be very variable. One of the best sources, the Japanese Gelidium amansii, is said to yield 25-35 per cent of its dry weight as agar.

The commercial utilization of seaweeds raises many issues. Having regard to present difficulties of overseas transport, it would seem natural to seek supplies from our own shores, possibly from the west and south-west of England, and the west and north-west of Scotland. The shores must be far enough from towns to escape serious pollution from sewage, yet sufficiently. accessible to the collector and to transport for the material collected. For most purposes, probably, the dried seaweed would suffice, and it could be washed and dried on the spot, before packirg.

When harvesting is regularly practised, it may be necessary to restrict the season of cutting and to regulate it in such a way that regeneration may occur by natural means. Much more information is needed as to the requirements of seaweeds for healthy growth and the reasons underlying the present distribution, especially of useful types. It is very probable that advances along these lines would lead to successful cultivation of desirable types like Gracilaria confervoides, Ahnfelditia plicata or Gelidium corneum, which are fairly common in some localities, or of Chondrus crispus and Gigartina stellata Batt., which are already known to be abundant in certain areas.

The commercial utilization further demands much work on the biochemical and technical side before the final stages of marketing can be reached. We thus require the services of the botanist, the ecologist, the biochemist, the technician and the financier. Yet the last word remains with the botanist, who com. bines the experience and judgment of a systematist with the prictical knowledge of the ecologist. For, in order that analyses may bear fruit, it is necessary that the right type of alga should be recognizable and recognized, its course of life understood and its reproductive periods utilized to the full.

\section{PHYSIOLOGY OF THE LUNG}

\author{
BY DR. O. A. TROWELL, \\ University of Edinburgh
}

$P$ ROF. B. Narayana, in his presidential address to the Physiology Section of the thirtieth Indian Science Congress held in January last, took as his subject "The Growth of Physiology as an Experimental Science". After tracing the history of experimental physiology from its origins with Ludwig and Claude Bernard, and giving some account of its current status, he proceeded to a review of recent work on the vasomotor and bronchomotor mechanisms of the lung, which subject he chose as an illustration of modern methods and the modern outlook in experimental physiology. This field of research has been developed chiefly by Prof. de Burgh Daly and his colleagues, first in Birmingham and later in Edinburgh. Prof. Narayana himself collaborated in some of the work in Edinburgh, and later he and his colleagues in India have made further contributions of their own.

In considering the physiological activity of the lung itself, we may remark that its respiratory movements are merely a passive response to changes in the capacity of the chest, that the gas exchange between blood and air is simply a process of physical diffusion, and that the only known physiological variables intrinsic in the lung itself are the calibre of the blood vessels and the calibre of the bronchi. The calibre of these tubes is controlled by the plain muscle fibres which form a large part of their walls. Vasomotor and bronchomotor changes, therefore, seem to be the principal intrinsic activities of the lung which call for investigation, and this is the field which Daly and his colleagues have successfully explored.

In the physiological investigation of any bodily organ there are, broadly speaking, two alternative lines of attack available. The first, or analytical, method seeks to isolate the organ in question from the disturbing influences of the rest of the body, preferably by excising it altogether, and, keeping it alive under fully controlled but somewhat artificial conditions, to analyse its functional responses to controlled stimuli. The second, or synthetic, method seeks to establish the part played by the organ in the integrated life of the whole animal, how it influences, and is influenced by, changes occurring elsewhere in the body. In the first method natural conditions must be sacrificed in order to secure full experimental control, and the results obtained indicate the physiological potentialities of the organ rather than its normal behaviour in the whole animal. The second method sacrifices full experimental control in order to maintain a natural condition of the organ; the results generally lack the scientific certitude associated with the former method, but when significant they reveal more truly the role of the organ in the normal life of the animal.

Daly, in his work on the lung, adopted the analytical approach. His success has been due in the first place to the development of a skilful technique whereby the lungs can be removed from the body and kept alive for several hours under artificial conditions, the blood circulation and respiratory movements being maintained by suitable pumps. The lung inflation, blood pressure, blood flow and other factors were under complete control and were recorded continuously. A second factor, no less 